\title{
Plasma glutathione S-transferase measurements after paracetamol overdose: evidence for early hepatocellular damage
}

\author{
G J BECKETT, B J CHAPMAN, E H DYSON, AND J D HAYES \\ From the University Department of Clinical Chemistry and Regional Poisoning Treatment Centre, The Royal \\ Infirmary Edinburgh
}

SUMMARY Plasma glutathione S-transferase (GST) measurements have been used to study early changes in hepatocellular integrity after paracetamol overdose and treatment with $\mathrm{N}$ acetylcysteine (NAC). Patients admitted within seven hours and successfully treated had raised or equivocal GST on admission and each showed a transient peak in GST approximately 12 hours after the overdose. Similar, though smaller changes in GST, were seen in untreated patients whose paracetamol level fell below the treatment line. The plasma GST concentrations in successfully treated patients were small compared with values found in patients who subsequently developed severe liver damage. The changes in GST concentration observed in patients who developed severe liver damage indicated that distinct early and late phases of paracetamolinduced hepatotoxicity occurred. Although the mechanism by which paracetamol exerts its early toxic effect is unclear, our data suggest that prompt treatment with NAC can successfully prevent both clinical and subclinical hepatotoxicity in this early period.

Paracetamol hepatotoxicity is caused by the production of an electrophilic arylating metabolite which binds covalently to macromolecules and initiates cell damage. This metabolite is normally rapidly inactivated by conjugation with glutathione but when the amount of paracetamol ingested is large, glutathione stores may be rapidly depleted and the toxic metabolite produces hepatocellular damage. ${ }^{1-4}$

Paracetamol induced hepatotoxicity can be prevented by administration of compounds such as $\mathrm{N}$-acetylcysteine (NAC) or methionine which replenish glutathione stores. ${ }^{5-8}$ Such treatment is generally given to patients whose plasma paracetamol concentration, related to the time since ingestion, lies above a line joining semi-log plots of $200 \mu \mathrm{g} / \mathrm{ml}$ at $4 \mathrm{~h}$ and $30 \mu \mathrm{g} / \mathrm{ml}$ at $15 \mathrm{~h} .^{9}$ If treatment is not initiated in patients with plasma paracetamol concentrations which lie above the treatment line, or if it is delayed more than 10 to 12 hours after the overdose, severe liver damage will occur in approximately $60 \%$ of patients. ${ }^{9}$ The earliest biochemical

Address for correspondence: Dr G J Beckett, University Department of Clinical Chemistry, The Royal Infirmary, Edinburgh EH3 9YW, Scotland. Received for publication 5 April 1984 evidence of acute liver damage becomes evident approximately 12 hours after the overdose but maximal abnormalities of liver function tests, particularly aspartate and alanine aminotransferase (AST and ALT) activity do not occur for two to four days. ${ }^{10}$

The degree of liver damage is usually assessed by the plasma AST or ALT activity and severe liver damage is regarded as being present when plasma ALT or AST exceeds $1000 \mathrm{IU} / \mathrm{l}$. In patients with moderate or mild degrees of paracetamol-induced hepatocellular damage, aminotransferase measurements may not reflect accurately the histological severity of liver damage. ${ }^{11}$

In contrast with AST, plasma concentrations of glutathione S-transferase (GST) correlate significantly with histology in patients with chronic active hepatitis. ${ }^{12}$ The high concentration of GST in human liver cytosol and their small size $(45000$ / $50000 \mathrm{Da})^{13}$ suggest that plasma GST concentrations should provide a very sensitive index of hepatocellular integrity because after cellular damage, GST would be expected to be released quickly and in considerable quantity. Preliminary work has suggested that this is so. ${ }^{14}$ is

In the present study we have used GST measure- 
ments to investigate the time course of hepatocellular damage in patients admitted after paracetamol overdose.

\section{Methods}

\section{PATIENTS}

Nineteen patients with paracetamol poisoning were studied. Seven did not require treatment and seven others were given NAC within eight hours of the overdose. Two patients were treated between 13 and 16 hours and three patients who presented after 17 hours were not treated. The alcohol intake before the overdose was noted in all patients. The plasma paracetamol concentrations and the ingestion treatment interval for each of the patients is shown in the Table.

The treatment regime involved administering 300 $\mathrm{mg} / \mathrm{kg}$ of NAC intravenously over a period of 20 hours. ${ }^{6}$ The first $150 \mathrm{mg} / \mathrm{kg}$ was given in $200 \mathrm{ml}$ of $5 \%$ dextrose over 15 minutes followed by a $50 \mathrm{mg} / \mathrm{kg}$ dose in $500 \mathrm{ml}$ of $5 \%$ dextrose over 4 hours and the two further $50 \mathrm{mg} / \mathrm{kg}$ doses each in $500 \mathrm{ml}$ of $5 \%$ dextrose over the next two eight hour periods.

Blood $(10 \mathrm{ml})$ was taken on admission and at frequent intervals until discharge. In four patients blood was taken at $\mathbf{3 0}$ minute intervals for the first $1 \frac{1}{2}$ hours after the initial rapid infusion of NAC.
The plasma was assayed for ALT using a Sequential Multiple Analysis with Computer System (SMAC), Technicon. Instrument Corporation, Basingstoke, UK, and for GST by a specific radioimmunoassay. ${ }^{15}$ Interference in the radioimmunoassay in vitro by NAC was not seen until concentrations of NAC exceeded $50 \mathrm{~g} / \mathrm{l}$, concentrations which could not possibly be achieved in blood using the treatment regime described above.

Reference ranges for ALT and GST were 10 to 40 IU/l and $0.5-3.0 \mu \mathrm{g} / \mathrm{l}$ respectively.

\section{Results}

\section{NO TREATMENT GROUP}

Early presentation $(<7$ hours after overdose)

Four of the seven patients with paracetamol concentrations below the treatment line had marginally raised GST concentrations on admission. In three of these patients GST concentrations rose further in the subsequent sample and in one patient, who had the highest paracetamol concentration of this group, this rise was marked (Fig. 1). Peak concentrations of GST were observed between four and 11 hours after the overdose and in all but one patient GST concentrations were normal on discharge. The rise in GST could not be attributed to acute alcohol ingestion because three of the four patients who

Table Paracetamol levels and ingestion-treatment interval in the 19 patients. The Table shows the plasma paracetamol concentrations at the time shown in the second column. The ingestion-treatment interval and peak GST and ALT levels are also shown.

\begin{tabular}{|c|c|c|c|c|c|}
\hline & $\begin{array}{l}\text { Plasma paracetamol } \\
(\mu g / m l)\end{array}$ & $\begin{array}{l}\text { Time after } \\
\text { ingestion }(h)\end{array}$ & $\begin{array}{l}\text { Ingestion-treatment } \\
\text { interval }(h)\end{array}$ & $\begin{array}{l}\text { Peak GST level } \\
\text { (multiple of upper ref. }\end{array}$ & $\begin{array}{l}\text { Peak ALT level } \\
\text { value) }\end{array}$ \\
\hline \multicolumn{6}{|l|}{ Not treated - early presentation } \\
\hline & 92 & $6 \cdot 5$ & NT & 0.4 & $1 \cdot 0$ \\
\hline & 99 & $4 \cdot 0$ & NT & 1.4 & 0.4 \\
\hline & 111 & $4 \cdot 5$ & NT & 1.8 & 1.0 \\
\hline & 140 & $5 \cdot 0$ & NT & 0.6 & 0.4 \\
\hline & 160 & $4 \cdot 0$ & NT & 1.5 & 0.7 \\
\hline & 160 & $4 \cdot 0$ & NT & 0.8 & 0.7 \\
\hline & 163 & $4 \cdot 0$ & NT & $9 \cdot 2$ & 0.5 \\
\hline \multicolumn{6}{|l|}{ Not treated-late presentation } \\
\hline & 42 & $26 \cdot 0$ & NT & 3800 & 180 \\
\hline & 50 & $42 \cdot 0$ & NT & 630 & 58 \\
\hline & 57 & $18 \cdot 0$ & NT & 9900 & 222 \\
\hline \multicolumn{6}{|l|}{ Treated-early presentation } \\
\hline & 165 & $7 \cdot 0$ & $8 \cdot 0$ & $13 \cdot 2$ & $1 \cdot 3$ \\
\hline & 167 & $4 \cdot 5$ & $8 \cdot 0$ & $5 \cdot 3$ & 1.0 \\
\hline & 171 & $6 \cdot 0$ & $8 \cdot 0$ & $21 \cdot 4$ & $3 \cdot 0$ \\
\hline & 182 & $5 \cdot 0$ & $7 \cdot 0$ & $8 \cdot 1$ & $3 \cdot 6$ \\
\hline & 189 & $4 \cdot 0$ & $6 \cdot 5$ & $4 \cdot 6$ & 0.6 \\
\hline & 233 & $4 \cdot 0$ & $4 \cdot 5$ & $25 \cdot 4$ & 0.8 \\
\hline & 279 & $4 \cdot 5$ & $5 \cdot 0$ & $10 \cdot 9$ & 0.7 \\
\hline \multicolumn{6}{|l|}{ Treated-late presentation } \\
\hline & 55 & $12 \cdot 0$ & $13 \cdot 0$ & 3700 & 280 \\
\hline & 109 & $15 \cdot 0$ & $16 \cdot 0$ & 10700 & 470 \\
\hline
\end{tabular}

NT $=$ not treated 


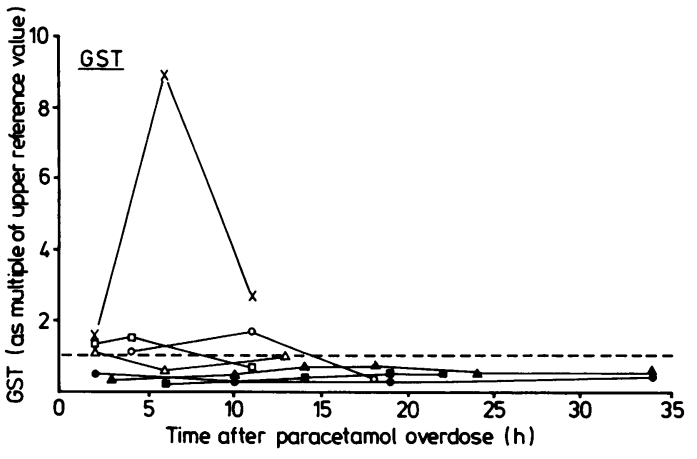

Fig. 1 Plasma glutathione S-transferase (GST) concentrations in seven patients admitted with a paracetamol overdose but who did not require treatment. The dotted line represents the upper limit of the reference range. Aminotransferase measurements were normal in all samples.

showed raised GST concentrations had taken no alcohol before the overdose.

Normal activities of ALT were found in all samples from all these patients (Table).

\section{Late presentation ( $>17$ hours after overdose)}

Three patients presented more than 17 hours after paracetamol overdose and each subsequently suffered severe liver damage with ALT activities $>1000$ IU/l (Fig. 2; Table). Each patients had GST concentrations on admission which were in excess of 150 times the upper limit of the reference range. In contrast ALT activities were no greater than 20 times the upper limit of the reference range. Each patient had raised but relatively stable GST concentrations (at 100-200 times the upper limit of the reference range) for a number of hours after admission. Between 38 hours and 45 hours, however, a further increase in GST concentrations occurred in two patients, with peak GST concentrations occurring between 50 hours and 70 hours.

Peak concentrations of GST preceded peak activities of ALT by appoximately five hours to 10 hours and the relative magnitude of the abnormality of GST at these peak concentrations was between 10 and 30 times greater than for ALT. The fall in GST was far more rapid than the fall observed in ALT concentrations.

\section{TREATMENT GROUP}

Early presentaion ( $<7$ hours after overdose)

Each of the seven patients in this group had raised or equivocal GST on admission and all showed a peak in GST between six and 12 hours after the

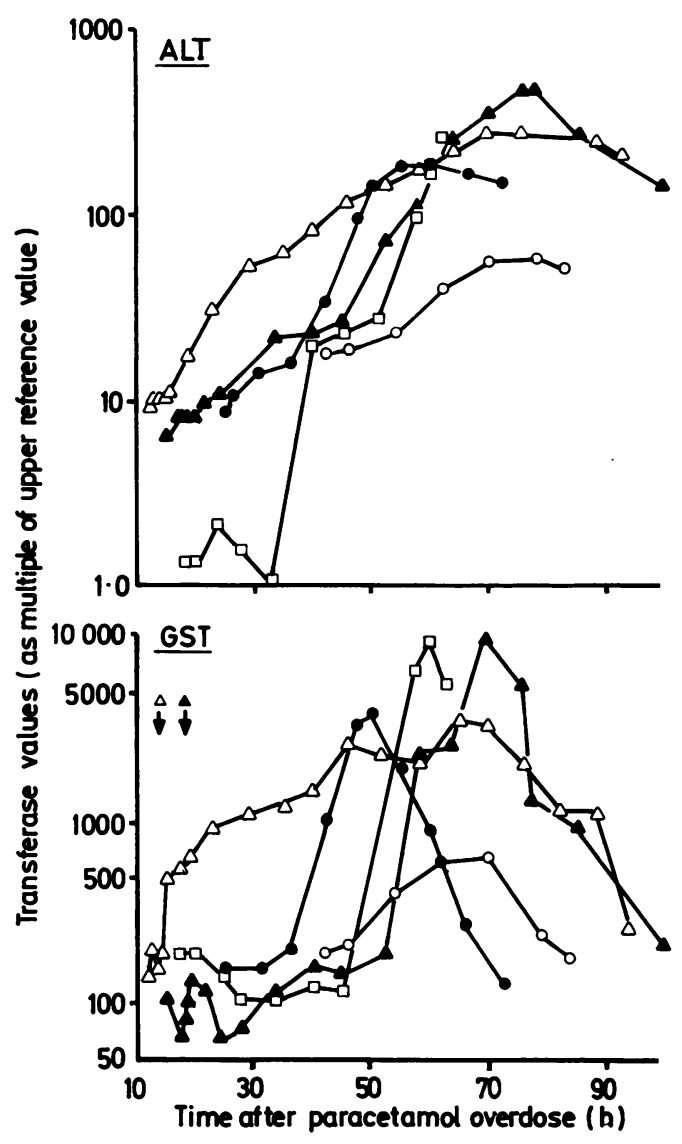

Fig. 2 Plasma glutathione S-transferase (GST) and alanine aminotransferase $(A L T)$ concentrations in five patients who developed severe liver disease after a paracetamol overdose. Two patients ( $\triangle$ and $\Delta$ ) were treated with $N$-acetylcysteine at the times indicated by the arrows. The remaining three patients were admitted too late for treatment.

overdose (Figs. 3 and 4). In all but two cases GST returned to normal within 24 hours. Only one patient admitted to consuming a large quantity of alcohol before taking the overdose. Three patients developed small abnormalities in ALT and AST which peaked 12 to 19 hours after the overdose.

Two of the seven patients had half-hourly blood samples taken in the period immediately after the rapid infusion of NAC, and each showed a marked rise in GST concentration in the first postinfusion sample (Fig. 4). These abnormalities in GST rapidly reverted to normal. No abnormality in ALT or AST was seen in any sample taken from these two patients. 


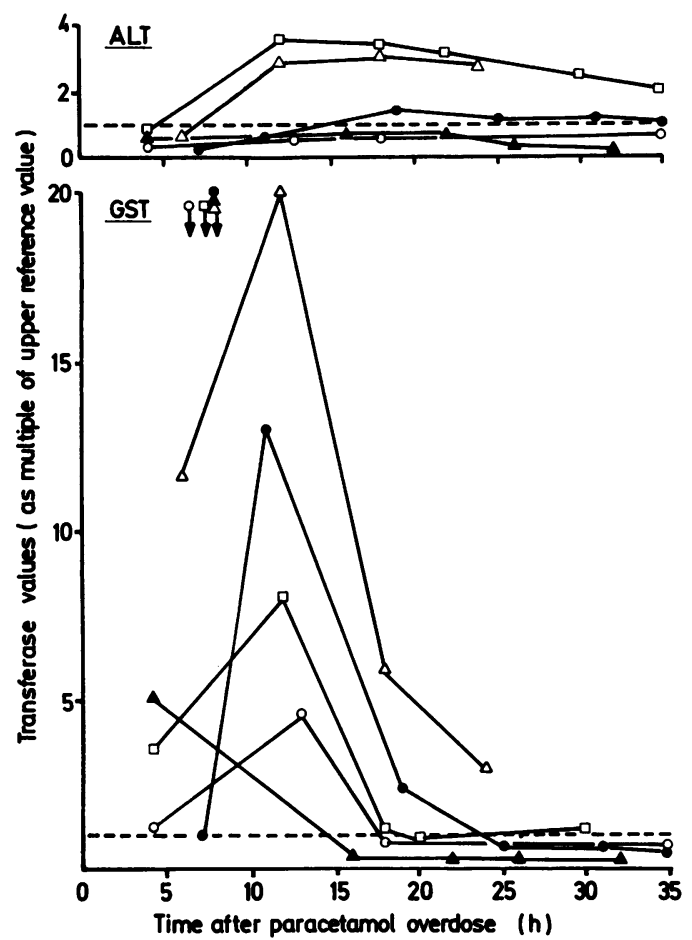

Fig. 3 Plasma glutathione S-transferase (GST) and alanine aminotransferase $(A L T)$ in five patients successfully treated with $\mathrm{N}$-acetylcysteine, administered at the times indicated by the arrows. These patients did not develop liver damage. The dotted line represents the upper limit of the reference range.

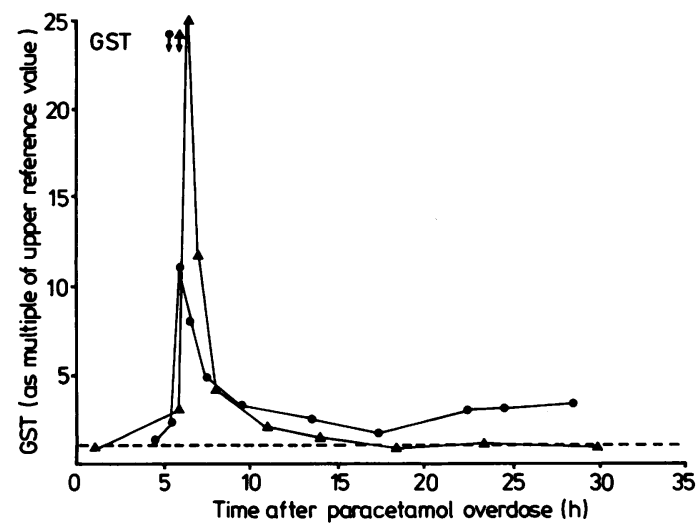

Fig. 4 Acute changes in plasma glutathione $S$-transferase (GST) after treatment with $N$-acetylcysteine. The two patients were treated at the times indicated by the arrows. The dotted line represents the upper limit of the reference range. Aminotransferase measurements were normal in all samples.
Late presentation (12-15 hours after overdose)

Two patients who presented 12 and 15 hours after overdose were treated with NAC. In each of these patients the admission and subsequent GST concentrations were similar to those seen in the late presentation-untreated group. In both patients NAC treatment did not prevent liver damage and a large increase in GST and ALT was observed.

Changes in GST concentrations appeared to occur in both patients after NAC infusion (Fig. 2). In one patient increased GST was observed in the first postinfusion sample and a peak in GST was observed one and half hours later.

The changes in GST observed in the second patient were more difficult to interpret. In this patient GST did not rise in the first postinfusion sample but in the following hour there was a large rapid increase in GST. This patient quickly developed severe liver damage as shown by the rising ALT activities. The concentrations of GST also continued to rise, but a significant decrease in the rate of change of GST was observed one and a half hours after NAC infusion (Fig. 2).

\section{Discussion}

The data presented show the extreme sensitivity of GST measurements in detecting acute cellular damage. Sixteen of the 19 patients had abnormal GST concentrations. In contrast, ALT activity was raised only in eight patients. Large rises ( $>100$ times normal values) in GST concentration were found on admission in all severely poisoned patients who were admitted more than 12 hours after taking paracetamol in overdose but such marked abnormalities in ALT activity were not noted until two days after the overdose.

The high incidence of abnormal GST and low incidence of abnormal aminotransferase concentrations is consistent with the findings of James et $a l^{11}$ who showed some degree of histological abnormality in 53 of $54(98 \%)$ patients after paracetamol overdose only $24(44 \%)$ of whom had abnormal AST activities.

We have shown that, after paracetamol overdose, abnormal concentrations of GST can be observed within four hours of the overdose. In patients who are successfully treated with NAC, peak GST concentrations are much lower than those found in severely poisoned patients indicating that in treated patients early paracetamol toxicity is clinically insignificant. If NAC treatment is not given within eight hours, GST concentrations in excess of 100 times the upper limit of the reference range occur 12 to 40 hours after the overdose. A subsequent further marked increase in GST then occurs at 40-50 hours, 
a rise which is consistent with previous findings that major liver damage occurs during this period. ${ }^{10}$

Our data, therefore, suggest that after a paracetamol overdose, in untreated patients, there are two distinct phases of hepatotoxicity. There is an early phase characterised by small abnormalities in plasma GST which occur within four hours and progress to more moderate abnormalites in plasma GST (approximately 100 times the upper limit of the reference range) by 40 hours. There then follows a second phase of hepatotoxicity characterised by severe liver damage and plasma GST concentrations in excess of 1000 times the upper limit of the reference range. The possibility of early liver -damage in patients taking a paracetamol overdose was first suggested by Prescott $e$ t al who noted that the plasma half life of paracetamol was prolonged from the outset in such patients. ${ }^{16}$

The early release of GST may be because of mild diffuse hepatocellular damage or may reflect damage to a specific population of cells which are more vulnerable to paracetamol. This putative increased vulnerability may be because of the increased concentrations of P450, subnormal intracellular concentrations of reduced glutathione or reduced conjugating ability. Whatever the cause, our data indicate that NAC treatment can arrest the early phase and prevent the late phase of paracetamol-induced hepatotoxicity.

The rise in plasma GST which we observed within 30 minutes of NAC infusion may have been coincidental and caused solely by paracetamol toxicity but the time course of the rise in GST suggests that NAC treatment may itself result in a release of a small amount of GST from the hepatocyte in to plasma. Studies on isolated rat hepatocytes tend to support this view because high concentrations of cysteine, the active metabolite of NAC, can produce cytotoxicity and leakage of intracellular enzymes. ${ }^{17}$ In man clarification of this point by control experiments - that is, NAC infusion in the absence of paracetamol poisoning and no NAC infusion after a paracetamol overdose, in patients requiring treatment and admitted within 8 hours - would be unethical. Comparison of peak GST values found in severe paracetamol-induced liver damage with peak values found in successfully treated patients indicates, however, that any liver damage resulting from NAC infusion is, clinically, insignificant.

It should be noted that GST is present in renal tissue in a concentration similar to that found in liver. ${ }^{18}$ It is likely, therefore, that a small percentage of the GST we have measured in plasma is of renal origin.

In conclusion, although the mechanism by which paracetamol exerts an early toxic effect on the liver is unclear, our data suggest that prompt treatment with NAC can successfully prevent both clinical and subclinical hepatotoxicity in this early period. It would be useful to ascertain whether methionine, the other commonly used treatment for paracetamol overdose $^{78}$ is as effective at preventing this early toxicity. Our data also show the sensitivity and potential which plasma GST measurements have in investigating, non-invasively, hepatotoxicity

We would like to thank Drs L F Prescott and A T Proudfoot for their advice and for allowing us to study patients under their care. We would also like to thank Professor L G Whitby and Dr A F Smith for their valuable help in the preparation of this manuscript and Mrs E Ward for her secretarial assistance. This work was supported by a grant from the Scottish Home and Health Department.

\section{References}

1 Mitchell JR, Jollow DJ, Potter WZ, Davies DC, Gillette JR, Brodie BB. Acetaminophen-induced hepatic necrosis. I. Role of drug metabolism. J Pharmacol Exp Ther 1973; 187: 185-94.

2 Jollow DJ, Mitchell JR, Potter WZ, Davies DC, Gillette JR, Brodie BB. Acetaminophen-induced hepatic necrosis. II. Role of covalent binding in vivo. J Pharmacol Exp Ther 1973; 187: 195-202.

3 Potter WZ, Davies DC, Mitchell JR, Jollow DJ, Gillette JR, Brodie BB. Acetaminophen-induced hepatic necrosis. III. Cytochrome P-450-mediated covalent binding in vitro. J Pharmacol Exp Ther 1973; 187: 203-10.

4 Mitchell JR, Jollow DJ, Potter WZ, Gillette JR, Brodie BB. Acetaminophen-induced hepatic necrosis. IV. Protective role of glutathione. J Pharmacol Exp Ther 1973; 187: 211-7.

5 Prescott LF, Park J, Ballantyne A, Adriaenssens P, Proudfoot AT. Treatment of paracetamol (acetaminophen) poisoning with $\mathrm{N}$-acetylcysteine. Lancet 1977; 2: 432-4.

6 Prescott LF, Illingworth RN, Critchley JAJH, Stewart MJ, Adam RD, Proudfoot AT. Intravenous Nacetylcysteine: the treatment of choice for paracetamol poisoning. Br Med J 1979; 2: 1097-100.

7 Prescott LF, Park J, Sutherland GR, Smith IJ, Proudfoot AT. Cysteamine, methionine and penicillamine in the treatment of paracetamol poisoning. Lancet 1976; 2: 109-13.

8 Vale JA, Meredith TJ, Goulding R. Treatment of acetaminophen poisoning. Arch Intern Med 1981; 141: 394-6.

9 Prescott LF, Critchley JAJH. The treatment of acetaminophen poisoning. Ann Rev Pharmacol Toxicol 1983; 23: 87-101. 
10 Proudfoot AT, Wright N. Acute paracetamol poisoning. $\mathrm{Br}$ Med J 1970; 4: 557-8.

11 James O, Lesna M, Roberts SH et al. Liver damage after paracetamol overdose: comparison of liver function tests, fasting serum bile acids and liver histology. Lancet 1975; 2: 579-81.

12 Sherman M, Bass NM, Campbell JAH, Kirsch RE. Radioimmunoassay of human ligandin. Hepatology 1983; 3: 162-9.

13 Jakoby WB, Habig WH. Glutathione transferases. In: Jakaboy WB, ed. Enzymatic basis of detoxication. Vol 2. London: Academic Press, 1980: 63-94.

14 Bass NM, Kirsch RE, Tuff SA, Saunders SJ. Radioimmunoassay of plasma ligadin. Gastroenterology 1978; 75: 589-94.
15 Hayes JD, Gilligan D, Chapman BJ, Beckett GJ. Purification of human hepatic glutathione Stransferases and the development of a radioimmunoassay for their measurement in plasma. Clin Chim Acta 1983; 134: 107-21. .

16 Prescott LF, Wright N, Roscoe P, Brown SS. Plasmaparacetamol half-life and hepatic necrosis in patients with paracetamol overdosage. Lancet 1971; 1: 519-22.

17 Vina J, Saez GT, Wiggins D, Roberts AFC, Hems R, Krebs HA. The effect of cysteine oxidation on isolated hepatocytes. Biochem J 1983; 212: 39-44.

18 Koskelo $\mathrm{K}$. Isoelectric focusing of glutathione Stransferase: Comparison of the acidic transferases from human liver, kidney, lung, spleen and placenta. Scand J Clin Lab Invest 1983; 43: 133-9. 